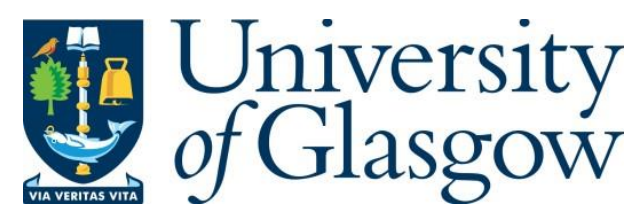

Billington, J., Longden, E. and Robinson, J. (2016) A literature-based intervention for women prisoners: preliminary findings. International Journal of Prisoner Health, 12(4), pp. 230-243.

There may be differences between this version and the published version. You are advised to consult the publisher's version if you wish to cite from it.

http://eprints.gla.ac.uk/175197/

Deposited on: 13 December 2018

Enlighten - Research publications by members of the University of Glasgow http://eprints.gla.ac.uk 


\section{A Literature-Based Intervention for Women Prisoners: Preliminary Findings}

$$
\text { Josie Billington, }{ }^{\mathrm{a}} \text { Jude Robinson, }{ }^{\mathrm{b}} \text { Eleanor Longden }{ }^{\mathrm{c}}
$$

${ }^{a}$ Centre for Research into Reading, Literature and Society; University of Liverpool, Liverpool;

${ }^{\mathrm{b}}$ School of Law and Social Justice, University of Liverpool, Liverpool;

${ }^{c}$ Institute of Psychology, Health and Society; University of Liverpool, Liverpool.

Corresponding Author: Dr Josie Billington, Centre for Research into Reading, Literature and Society (CRILS), 213 Whelan Building, University of Liverpool. L69 3GB, UK. Tel: 0151 794 2734. Email: jbilling@liv.ac.uk 


\begin{abstract}
Purpose - This study investigated whether Shared Reading (SR), a specific literature-based intervention, is transposable to a prison context and whether any of the mental health and wellbeing benefits identified in other custodial and non-custodial settings were reported by women prisoners.
\end{abstract}

Design/methodology/approach - Thirty five participants were recruited within an all-female maximum security prison and attended one of two weekly reading groups. Qualitative data were collected through researcher observation of the reading groups; interviews and focus group discussions with participants and prison staff; interviews with the project worker leading the reading groups; and a review of records kept by the latter during group sessions. Findings - Attendance rates were good, with nearly half of the participants voluntarily present at $\geq 60 \%$ of sessions. Two intrinsic psychological processes associated with the SR experience were provisionally identified, 'memory and continuities' and 'mentalisation,' both of which have therapeutic implications for the treatment of conditions like depression and personality disorder.

Limitations - Limitations included the small sample, lack of control for confounding variables, and constraints imposed on data collection by the custodial setting.

Originality/value - Although more controlled research is required, the findings indicate that women prisoners will voluntarily engage with SR if given appropriate support, and that the intervention has potential to augment psychological processes that are associated with increased wellbeing.

Key words: reading therapy; personality disorder; mentalisation Article Type: Research paper 


\section{Introduction}

The care of those suffering mental health issues in prison has been recognised as a burgeoning problem in need of urgent solutions and management in the UK, Europe and the US over the past decade (Anasseril, 2007; Wilper et al., 2009; Shaw et al., 2010; Collier, 2014). The mental health of women prisoners has become a barometer of this crisis, given that, while women are a minority population in prisons and are often incarcerated for minor offences, they have a significantly higher risk of developing psychiatric symptoms than men: the risk is double that of men for suicidality and hallucinations, for example (Thigpen, 2004; van den Bergh et al., 2009; Shaw et al., 2010).

Policy guidelines in the UK have long advocated that prisoners receive the same level of healthcare as they would in the wider community (Joint Prison Service and National Health Service Executive Working Group, 1999) and the evidence for this necessity in the US is overwhelming (Allen, 2008; Torrey et al., 2010). However, while reviews of custodial mental health services in Britain have welcomed the increase of in-reach services and provision which models community healthcare, they have also stressed the need for greater investment on the grounds that "prisoners remain more socially excluded than all other groups in society, with a higher risk of suicide and self-harm, plus a higher level of serious mental illness than the general population" (Brooker et al, 2007; p.9). Early intervention and diversion for offenders with mental health problems have also been recommended by the UK Department of Health ([DoH], 2009). Specifically, suicide, self-harm, and personality disorder (PD) have been identified as research priorities in prison mental health, with a particular need for evaluation of psychosocial interventions and a review of 'what works' in alleviating these problems. Consistent with calls for improved provision and quality of 
mental healthcare in the general population ( $\mathrm{DoH}, 2011,2014)$, there is a clear need to identify and extend the range of effective therapeutic strategies for prisoners, and to discover new ways of engaging those unable or unwilling to access existing interventions.

This study was conducted in the UK through a partnership between researchers from the Centre for Research into Reading, Information and Linguistic Systems (CRILS) at the University of Liverpool, HMP Low Newton, Durham, and The Reader (TR), a nationally recognised centre for the promotion of reading and positive mental health. The project was approved by the Northern and Yorkshire Research Ethics Committee, and was commissioned and funded by the UK National Personality Disorder Team (NPDT, UK National Health Service/Home Office).

\section{The Intervention}

In the Western world, literature's potential power as a therapeutic tool has been widely recognised and documented (Gold 2001; Dwivedi, 1997) and there has been significant uptake in recent years of the use of fiction and poetry in mental health care (McArdle and Birt, 2001; Pehrsson and McMillen, 2005; Baker, 2006). Innovative literary initiatives within prison contexts have also increased notably over the last decade. Wally Lamb's story-telling work with female prisoners in New York (Lamb, 2004), Jenny Hartley and Sarah Turvey's Prison Reading Groups initiative (Hartley and Turvey, 2009) and Ann Walmsley's Prison Book Club project (Walmsley, 2015) are instances of a growing trend for using literature as a humane intervention for the improvement of mental health and wellbeing in secure settings (Cocking et al., 2004; Scott Douglas, 2007; Ross, 2011; Heard et al., 2013).

The Reader (TR) is an award-winning charitable social enterprise that aims to connect people with great literature, and to create environments where personal responses to books are freely shared in reading communities in every area of life. TR currently delivers almost 
400 weekly groups across the UK and in Europe in a diverse range of health and social care settings, and has demonstrated positive outcomes for populations that include adults with dementia (Billington et al., 2013), mental health difficulties (Longden et al., 2015), chronic pain (Billington et al., 2014), neurological conditions (Robinson, 2008), and those experiencing social disadvantage (e.g., vulnerably housed or recovering from substance dependence: Hodge et al., 2007). The intervention is delivered by TR-trained project workers, who facilitate dynamic discussions of a text with 2-12 group-members via an exploration of participants' subjective reactions to it. Specifically, SR differs from the format of traditional reading groups in that material is unseen in advance and communally read aloud during the session, a model that encourages 'interpersonality' both with the book, its author and characters, and with other group members (Davis, 2009). Regular breaks in the reading further encourage participants to reflect on what is being read and how it might relate to their own lives.

The key elements of SR, as identified in pilot studies in non-secure settings (for example Billington et al., 2011, Dowrick et al., 2012), are:

- a rich, varied, non-prescriptive diet of serious literature, including a mix of fiction and poetry;

- the literature's being made to 'live' in the room, through skilful reading aloud ensuring the book or poem is accessible to all participants, regardless of levels of literacy, educational, ethnic or cultural background;

- the sharing of personal ideas and feelings in response to literature - inclusive of everyone, knitting people together in both the reading experience and a supportive community; 
- voluntariness of participation - enabling readers to control their own involvement, contributing as much or as little as they like, according to mood and confidence levels;

- weekly regularity - offering valuable continuity and structure for people whose lives may be chaotic or empty.

In reviewing available evidence for SR, Dowrick et al. (2012) suggested that the approach "harnesses the power of reading as a cognitive process, but also acts as a powerful socially coalescing presence" (p.16). Elements of SR cited as contributing to improved wellbeing include: shared literature's developing both a deep sense of human selfhood and a more emotionally-sharing small community (Billington, 2012); presentness and thoughtfulness in relation to private emotion, where the text is not a didactic self-help text but closer to a personal speaking voice (Billington et al., 2014); recovery of lost or forgotten aspects of being, where the fiction or poetry helps close the rift between a current ill self and a former well self and encourages greater integration of fragmented parts of the self into a functioning whole (Gray et al., 2016); the shared group setting, and the literature within it, offers a caring alternative (and partial counter) to the stigma of being judged, threatened or ignored within a hostile or indifferent society, enabling moments of sudden reflection and realisation in relation to past experience of shame, loss or pain (Longden et al., 2015).

Related research in the field of reading and neuroscience has suggested that the inner neural processing of language when a mind reads a complex line of poetry has the potential to galvanise existing brain pathways and to influence emotion networks and memory function (Davis et al., 2008, 2012). Together with qualitative findings that reading 'stimulates metacognition and high-level mentalisation in relation to deepened and expanded emotional investment in human pursuits (created by the book)' (Longden et al., 2015), it is possible, a recent neurological study has suggested, that some of the benefit associated with reading may 
come from 'diverting individuals away from processing their struggles via ingrained and ineffective channels and towards more diverse, novel and effective reasoning options' (O’Sullivan et al, 2015).

As a wellbeing intervention, the value of SR has been recognised by Dr David Fearnley, the Royal College of Psychiatrists 'Psychiatrist of The Year' (2009), who deemed it "the most important development in mental health practice" in his career (quoted in The Reader, 2015). Although much of the evidence base is derived from community settings or health care/rehabilitation centres, SR has also been implemented in a range of forensic settings. In addition to high and medium secure mental health units, including male, female, young peoples' and Learning Disabilities wards, SR has also been delivered in eight UK prisons across the UK since 2008. A narrative review of SR delivery in HMP Liverpool and HMP Hydebank Wood (Billington, 2012) reported that fiction and poetry appear to demand the kind of continuous mental agility and moral/emotional flexibility that few activities (including other arts-related ones) can demand with comparable immediacy and directness.

There is particular reason for studying the potential impact of such an intervention in secure settings, where the incidence of borderline personality disorder (BPD) is high. Although most studies of effective psycho-social interventions are too small-scale to be conclusive or generalisable, the evidence is strongest for the effectiveness of cognitive behavioural and dialectical behaviour (as against purely behavioural) therapies and promising results have emerged from trials of Cognitive Behavioural Therapy (CBT) and derived therapies adapted to the needs of parasuicidal BPD patients (Davidson et al., 2006; Low et al., 2001; NICE, 2009; Weinberg et al., 2006). These interventions target emotional and interpersonal deficits found in BPD - emotion regulation, interpersonal effectiveness and 'mindfulness' (focusing on present experience thus reducing the tendency to dissociate). 
Taken together, there are grounds for inferring a beneficial role for SR engagement in custodial settings and a rationale for developing the evidence base for its application and methods of impact. As such, the brief and aims for the current study, commissioned by the UK National Personality Disorder Team (NPDT), were: (1) to assess whether SR transposes from mental health settings into a prison context, and how far the benefits which accrue to participants in non-secure settings are in evidence for those taking part in a secure setting; (2) to undertake preliminary investigation, within the limitations imposed by the prison environment (i.e. no audio/video-recording), as to whether and how SR might be considered a psychosocial intervention with implications for the treatment of personality disorder; and (3) to contribute to an emerging body of research relating to reading as promoting mental health and wellbeing in adults with high levels of need. The NPDT stipulated that the research be carried out in a specified high secure prison (HMP Low Newton Durham, a women's prison) with a significant personality disorder population. (The study was intended to extend to HMP Frankland, a men's prison, but the plan proved impracticable.)

The NPDT had a specific interest in ascertaining how far SR could help shift internal paradigms or the rigidified default models of self and story which characterise personality disorder. Partly on the strength of the findings of this study, The Reader has been commissioned to deliver SR around the UK in all 18 of the Psychologically Informed Planned Environments (PIPES) first developed by the NPDT (Joseph \& Benefield, 2012).

\section{Materials and Methods}

\section{Participants}

HMP Low Newton provided participant demographic data to the researchers (age, literacy levels, admission and release dates) for the purposes of programme implementation. Age and 
literacy levels are reported below. No other participant demographic data was obtained for this study.

Thirty-five women were recruited to the study. The age range was 18 to 62 , with most participants within the age range 30-50, thus: under $20=$ one participant; $20-30=$ six participants; $30-40=$ twelve participants; $40-50=$ seven participants; $50-60=$ eight participants; $60-70=$ three participants.

Literacy levels were recorded for thirty-four of the thirty-five participants. Seven participants were classified at Adult Literacy Level 2, (National Curriculum level 6, GCSE Grades A-C); over half participants (twenty-one) were classified at Adult Literacy Level 1 (National Curriculum level 5, GCSE Grades D-G); five participants were classified at Entry level 1 (National Curriculum, levels 3-4 - expected of an eleven year-old) and one participant was classified at Entry Level 2 (National Curriculum level 2 - expected of a seven year old).

Many had been diagnosed with mental health issues, ranging from mild to moderate depression to (BPD). All were White British.

Although there were no formal exclusion criteria, women who were not permitted to move to other areas of the prison (restricted status), or who found it difficult to interact with women in other areas of the prison, were less likely to be able to access the unit where the group was held.

The project commenced directly before UK prisons declined to let prisoners have access to books in 2013); this prohibition did not therefore impact on the motivation of the women to participate in the study.

\section{Procedure}

The study was conducted at HMP Low Newton, an all-female maximum security prison in the north of England. Two weekly reading groups, each lasting two hours, were established 
by a TR-trained project worker and ran in three venues within the prison: in Primrose Wing (developed in 2006 to address the needs of women as part of the Dangerous and Severe Personality Disorder [DSPD] Programme in England and Wales); the Learning Shop and Library; and in the association room close to the Library. All participation was voluntary. Consistent with the standard SR model, the groups employed a widely varied range of literature including poetry, short stories and novels crossing centuries and genres, according to the interest of the participants and guided by the project worker (for a full reading record, see Table 3). A wide range of literature has always been integral to the SR model (Davis, 2009; Billington, 2011), intended to offer a rich rather than narrow diet, based on the seriousness and quality of the literature, past experience of 'what works' in read aloud groups, and the agreed choice of the group members themselves.

- Table 1 here -

Two researchers (JR and JB) observed both groups over a total of seven visits throughout the research period (1 July 2011 to the end of June 2012). Although they did not participate in the sessions themselves, a number of interviews and focus group discussions with participants were conducted after the groups had finished. Further interviews and group discussions were organised with workers at the prison, including custodial, clinical, and Library staff.

The methodological orientation was based in 'realistic evaluation' (Pawson \& Tilley, 1997), which investigates complex open human systems and captures a rich picture of action and experience in its full social context. As digital recording was not permitted within the prison, data was collected in the form of contemporaneous field notes. As JR is an anthropologist, she is familiar with theory and practice of note taking (Emerson et al, 2007; Osborne, 2012). To ensure that participants were genuinely willing to be interviewed, the women were initially approached individually or in pairs by the project worker.. If they were 
interested in talking to a researcher, they were later contacted and the researcher went through the Project Information Sheet with them, and answered any questions the might have. Only when the women had considered and discussed the project were they asked to sign copies of the consent form.

At the individual interviews, JR reiterated that the researchers were interested in the womens' experiences of taking part in the reading group at Low Newton and that, in order to understand those experiences, we also wished to know about any past experiences the women may have had around reading, or being read to (Mischler, 1986; Riessman, 2008). Using a biographical and narrative approach, JR suggested that the participants start by telling something of their earliest memory of reading, or being read to, moving on to further memories of personal significance, and finishing with their experience of taking part in the reading group (Coffey \& Atkinson, 1996; Silverman, 2012) . JR made clear, however, that participants could begin wherever they liked, could take as much time as they needed, and that everything they said would be treated in complete confidence.

Audio-recorded interviews were also conducted with the project worker, who additionally provided access to the reading group logs; all direct quotes below are taken from these two sources. All recorded data were transcribed, and after reading and re-reading the transcripts and the fieldnotes a number of times, the transcripts were coded line by line and the fieldnotes were annotated to identify codes which were later organised into more coherent overarching themes (Sanjek, 1990).

Finally, a short report of the research findings (Robinson and Billington, 2014) was made available to participants via the TR project worker. 


\section{Ethics}

Ethical approval was received from the Northern and Yorkshire Research Ethics Committee (which is specially constituted for reviewing and approving research undertaken in secure and forensic settings) and secured National Offender Management Service (NOMS) approval. The project was conducted on principles of good research governance in line with the UK Economic and Social Research Council Framework for Research Excellence (2012) and the British Sociological Association guidelines for the conduct of ethical research (2002). We sought informed and ongoing consent from all participants and worked closely with prison and associated staff to ensure that the women agreed to be approached by the researchers and were well enough to take part.

\section{Findings}

\section{Attendance}

There was a significant correlation across the sample between residence at the prison and weekly attendance $\left(r_{s}=.61, p=.001\right)$. Separate attendance rates for the two groups are shown in Figure 1.Given the custodial setting these rates can be considered high, as some women had other appointments/activities scheduled at the time of the groups which were either compulsory, or for which they were reluctant to "complain" by seeking permission to rearrange. As such, it is likely that unconstrained participation would have been even higher. Indeed, some women were concerned that if they were moved to another prison SR would not be available to them, expressing a desire that SR should be accessible wherever they were, including upon release into their communities.

- Figure 1 here - 


\section{Low Newton SR and non-custodial SR}

Not only was the model and choice of literature unchanged in key respects from the one used in community mental health settings, the study also isolated four significant areas of improved wellbeing of which at least three are consonant with published findings from studies of community reading groups (Hodge et al., 2007; Davis 2009; Billington et al. 2011; Longden et al., 2015). These areas were: Social (encouraging integration, and attracting more solitary and less socially engaged individuals; promoting respect and tolerance for others' views; enhancing communication skills); Emotional/Psychological (promoting a sense of escape and relaxation; encouraging self-expression); Educational (attracting participants from a range of literacy and educational achievements; willingness to engage with 'difficult' books; voluntariness and motivation in respect to the activity). In addition, the study found evidence of enhanced organisational wellbeing, with staff's expectation of inmates positively challenged by the latter's willingness to engage with 'difficult' books and their motivation in respect to the activity (Robinson and Billington, 2013; Robinson and Billington, 2014).

Within the trends outlined above, however, the researchers isolated a number of key areas which (i) have emerged as significant aspects of the participants' responses to the literature; (ii) appear to have contributed to the beneficial effect of SR in the context of Personality Disorder especially; and (iii) are likely to reward further investigation in a future research study as possible psychological mechanisms and processes for helping to improve wellbeing as a function of SR.

\section{Potential Psychological Mechanisms}


When evaluating how and why the women engaged with the literature, qualitative analysis provisionally indicated two intrinsic psychological elements of the SR experience: memory and continuities and mentalisation.

\section{Memory and continuities}

The power of SR to elicit articulate personal memory was strongly in evidence within the groups, which could be generally divided into three types:

1) Convivial sharing. This feature was characterised by playful or humorous recollections of mutual experiences relating to childhood and relationships, as well as to the legal and penal system. For example, Barry Hines' A Kestrel for a Knave moved participants to reminiscence about childhood misdemeanours. Likewise Great Expectations elicited humorous exchanges around past encounters with lawyers, men who take pride in DIY and gardening, and amusing anecdotes relating to the transport of prisoners, in which "the parallels with the Dickens chapter were remarkable.” In turn, a reading of Robert Browning's 'One Way of Love,' elicited memories of adolescence, wherein the unrequited love described in the poem was "related to teenage crushes and the lute substituted by an electric guitar."

2) Individual recollection of serious or watershed events. There were numerous examples of the texts evoking incidents of profound, subjective significance. For example reading 'Flight' led one participant to reminisce extensively about her own family and her experience of leaving home. In turn, another participant compared herself to Pip, the protagonist of Great Expectations, commenting on how his inability to "act it out" was reminiscent of her own teenage experiences. The predicament of Miss Havisham from the same novel was interpreted by another participant using modern understandings of trauma and mental illness, reflecting on "how strong the sense of embarrassment and denial can be" 
before disclosing that she had herself been housebound for four years, and providing a moving description of her sense of a shrinking world and the difficulty of change.

3) Awareness of the past as a possible source of solace as well as regret. Finally, the literature also elicited reflections on the past as embodied events that shape one's life in both positive and negative ways. For example, at the conclusion of one session, a participant refocused the group's attention on the final lines of Ted Hughes's poem, 'The Horses', before speaking eloquently of her belief that, regardless of what you have done, there remain "beautiful moments in your past that can't be taken from you."

These are representative samples of memories which were a persistent feature of the sessions. Much of the 'recollection' was concerned with a past life outside prison, which was continuous and concurrent with a present life, inside prison. For example, Great Expectations elicited discussions about planned meals on release, as well as serious debates about class, age, and the advantages of keeping one's private and professional selves separate in order to survive. There was also a consistent preference for texts containing evocations of the natural world, wherein literature could help discover or develop a more composite, multidimensional experience than might be readily realized in a captive environment. Indeed, "Participants are sometimes shocked by the sudden sense that mere print on thin paper can transmit such a...full sense of life. Fiction and poetry can convey the very feel of the sensory world - the sun on one's face, rain on one's head, sand between one's toes' (Billington, 2012, p.73).

A further notable issue was participants' use of literature as a connection to a continuing and ongoing life, and their frequent eagerness to share the reading experience with loved ones. One participant, attending her final session before release, thanked the group leader on the grounds that "it was the only thing that has kept [her] sane" and stated that she intended to read Great Expectations aloud with her husband. Another participant spoke of 
sending her husband a written synopsis of the group discussions, whereas others described sharing books and poems with children and grandparents. The possibility was also enthusiastically discussed of conducting reading groups during family visiting days.

Finally, the texts also appeared to offer a sense of continuity within the prison and between institutions. When Great Expectations was underway, one participant declared an intention "to take the book back to [her] pad and finish it tonight." Another reader took copies of Carol Ann Duffy's 'Big Sue' and 'Now Voyager' to post on her wall. One participant, who was being transferred to another prison, asked about the possibility of joining an equivalent group there. It later transpired that this woman had written to another member of the group to say she had loaned Great Expectations from the prison library upon arrival and had since finished it.

\section{Mentalisation}

Many group sessions exemplified the contention that literature can increase the capacity to make sense of oneself and others in terms of subjective states and mental processes (Galgut, 2010). Understanding the thoughts, feelings, and wishes of oneself and other people ('mentalisation') is a major developmental achievement, believed to originate in the context of infant attachment relationships (Meins et al., 1998), and which strongly influences subsequent social and interpersonal behaviours (Fonagy, 2006). In turn, some theorists have claimed that unstable or reduced mentalising capacity is a feature of several psychological conditions, including BPD (Fonagy \& Bateman, 2008) and schizophrenia (Liotti \& Gumley, 2008).

As Billington (2012) has observed: "What is striking about the conversations which take place in prison (as in all [SR] groups) is that participants routinely inhabit not just one position or perspective 'not their own'... Rather, even as readers predict forwards, they must 
enter two or sometimes more perspectives at the same time" (p.74). Correspondingly, mentalisation was a common, even intrinsic, phenomenon within the current study. One example, from the group's response to John Steinbeck's The Pearl, demonstrates the degree to which inhabiting alternative viewpoints is intrinsic to SR for most participants. The reflections of the TRO worker capture this as follows:

The quietness of this group was even more pronounced this week as we reached the end of The Pearl. The tragic end really got to us all. One participant, normally very quiet, shook her head at the end of the book and said "that was really, really good. Really, really sad but in a good way." All members were keen to impress how much the story has meant to them.

During the reading itself, all the women had much to contribute in discussing the story, including issues of injustice, the corrupting potential of money, choosing who to trust, the morality of the class system, and the value of material possessions relative to the love of family. As well as relating these dilemmas to their own lives, participants were additionally able to inhabit the internal world of the characters. For example:

[Participant] A in particular was adamant that Kino should not give into the poor offer of the sellers. Others were less sure because of the disempowered situation of Kino and his family. It was difficult to get people speaking today not because they were uninterested but because their attention was so rapt. There was an animated conversation about Juana's reaction to Kino's violence, with one participant drawing parallels with her own life. Another was moved by the change in Kino, thinking he'd "sold his soul" but that it was important for him to keep on fighting.

There were also specific examples of mentalisation in addition to the more general expressions described above. SR's capacity to foster mentalising tendencies was particularly highlighted by one member in whom such cognitive activity was unaccustomed. This participant had presented some challenges to the TR project-worker, especially in some of her 
highly individual responses to the poetry (e.g., dismissing alternative interpretations to her own as 'misreadings'; ostensibly hinting that others members' difficulty to "get" a

Shakespeare sonnet was due to personal intellectual failings; rejecting a poem that she alone was unmoved by as unnecessarily complex and blaming the worker for failing to read the poem in an accessible way). These views were often steadfastly retained by the participant, who was resistant to any modification of them from the worker or other members. However, following an explicit statement by the worker around the expectation that numerous contradictory views were acceptable and expected in an absence of one "right" answer, a turning point occurred during a reading of Great Expectations. The participant "thoughtfully commented that Miss Havisham was too feeble and this led onto an important discussion of the latter's character and the steely malice at her core." From this point on it was possible to trace a distinct, albeit inconsistent, shift in mentalising activity in this participant, whereby she gradually became more adjusted to the expectation and/or stimulus occasioned by (i) the literature itself and (ii) the shared reading of the texts, to mentalise her own and others' experience, where 'other' refers both to members of the group and the human presences personified in the texts' characters. It is perhaps significant that these changes occurred in relation to prose narrative, wherein sustained imaginative attention and sympathetic engagement with other views and worlds is demanded (in contrast to the briefer intensity of poetry).

\section{Discussion}

The current findings add to existing evidence demonstrating SR's utility in a prison context. Firstly, its engagement potential was confirmed by the voluntariness of the women's attendance, despite competing appointments, and their commitment without expectation of 
material reward ("getting something out of it without wanting something from it" as a member of staff expressed it) (Robinson and Billington, 2014). Secondly, there was evidence of substantial cognitive and emotional engagement with the reading material. There were repeated instances of the literature spontaneously eliciting specific and vivid autobiographical memory or moments of recognition, as well as of the reading activity encouraging a capacity (sometimes demonstrably progressivin view of research evidence for memory impairment during periods of depression (Lemogne et al., 2006) and low self-esteem (Williams and Scott, 1988). Contemporary goals and self-perceptions influence recollection of the past, to the extent that is there not only a lower retrieval of positive memory, but also a lack of specificity in the recollection. Autobiographical memory becomes characterised by over-generality, with a tendency to recall sequences of events or time periods and/or extended or repeated events rather than specific episodes or instances, and this is more evident in positive than in negative memory. Depressed people additionally find it difficult to imagine present or future alternatives, since they are less able to retrieve specific episodes from the past which support them in a 'better' view of themselves. In this light, the diverse modes of remembering the past which occurred in the reading group have potential significance for future therapeutic practice and research. In this respect the power of literature to reconnect people to their former lives and selves by evoking and stimulating memory has been especially noticed in the use of SR in dementia (Billington et al., 2013; Centre for Research into Reading, Literature and Society, 2014), where a sense of connected life and identity is often demonstrably restored. In prison, such rescue work is perhaps equally important, if the ideal of rehabilitation is founded upon the fostering or creation of a more responsibly integrated self, as a preliminary to the return to civic life. Given the potential significance of autobiographical memory in grounding the self - providing coherent narratives which help 'organise' a sense of identity across time - SR might offer the kind of cognitive activity 
which can help recover the meaning and value of personal memory, and build resilience against vulnerability to further breakdown.

Secondly, SR offers a way to combine exploration of the private self with more externally-focussed, social elements of identity, allowing readers to share experiences of a book whilst testing their personal responses against those of other people. These are dynamic encounters where individuals negotiate and re-think meaning in the process of talking and listening to one another. In line with courses designed to help rehabilitate prisoners on parole, such as 'Enhanced Thinking Skills' reading groups create 'an inquiring and critical sociability' (Turvey and Hartley, 2008). Indeed, the capacity of communal reading to bestow participants with a sense of subjective and shared experience at the same time (Hodge et al, 2007) resonates with recent research findings on the importance of mindfulness, verbalised recognition and reflective self-agency in reducing incidents of self-harm. The habitual practice of understanding from a range of imagined positions and viewpoints demonstrated within the groups, as well as the progress in mentalisation made by participants for whom this was an unaccustomed cognitive activity, is also instructive of SR's potential to galvanise new forms of mentality. In this respect, the clinical implication of the mentalisation-based model of PD and other psychological conditions posits that, for treatment to be successful, it should have mentalisation as its focus and at the very least stimulate development of mentalising as a by-product. That is to say, it needs to address the patient's capacity to think about behaviours and relationships, rather than emphasising relational or behavioural patterns themselves; it must seek to enhance and facilitate flexibility of thought processes, tease out understanding and generate alternative perspectives (Fonagy and Bateman 2008; Harari et al., 2010). Though the findings outlined above in relation to SR's capacity to stimulate mentalisation are exploratory only, they lay the foundation for future research into its efficacy as treatment or complementary aid. 


\section{Limitations}

The findings must be interpreted in view of several limitations. Primarily this included constraints on the research process imposed by the custodial setting. For example, the researcher was not permitted to talk to the women in their rooms, and depending on the participant and setting, some encounters had to be arranged in view of a member of the security staff, which may have inhibited disclosure. As part of disciplinary procedures, some women's free time was restricted or withdrawn, and as they were only able to attend approved activities were not available to talk to the researcher outside these times and sometimes were even unable to attend the groups. When leaving the Library/Learning Shop to talk to the women, the researcher needed to be escorted by custodial staff or the TR worker, which further limited interview time depending on their availability. Some of the sessions were also interrupted by early 'movement', in which women were required to immediately return to their rooms, meaning the groups were unable to finish reading the text and the researcher was unable to speak with them either as a group or individually.

Although it was made clear that participants could refuse permission to have the groups observed, or decline consent for interviews, some women may have preferred not to join the groups during the study. Given the brief and sporadic nature of the research visits, there may also have been women attending the groups that the researcher never met and/or never spoke to individually. It was additionally the case that women who wanted to speak with the researcher were unable to, either as a result of limited time during her visit, or their own unavailability (e.g., a conflicting appointment).

Finally, the results would have been improved by quantitative analyses derived from standardized assessment instruments, such as measures of anxiety, depression, or quality of life. The inclusion of a control group engaging in a comparison activity would also have 
strengthened the conclusions. As such the generalizability of the findings are limited. Other areas not addressed in the current study, but which are strongly suggested as targets for future enquiry, include: how to engage younger women, particular those serving shorter sentences; identifying what reading materials 'work' with different groups of women and why; and determining the psychological mechanisms and processes which might help to improve wellbeing as a function of SR participation.

\section{Conclusions}

The current study demonstrates that SR is sufficiently adaptive to transfer to custodial settings, and that women will voluntarily engage with it given appropriate support and assurances. It also adds to an existing evidence base indicating that SR has the capacity to promote wellbeing, and enhance a sense of achievement, self-worth, and social participation. However, in addition to being an intrinsically enjoyable activity in and of itself, our preliminary findings for SR's beneficial effects on cognitive processes like memory consolidation and mentalisation are an avenue for further study in terms of its potential as a therapeutic intervention.

\section{Acknowledgements}

This study was supported by funding from the National Personality Disorder Team and is adapted from the report 'An Evaluation of a Pilot Study of a Literature-Based Intervention with Women in Prison' published by the Centre for Research into Reading, Literature and Society at the University of Liverpool. We would like to thank the staff of HMP Low Newton, project workers at TR, all participants who took part in the reading groups, and the 
generous efforts of Lindsey Dyer (Mersey Care NHS Mental Health Trust), in helping to secure the research partnership with HMP Low Newton.

\section{Author Disclosure Statement}

No competing financial interests exist.

\section{References}

Allen, S., (2008), "Mental Health Treatment and the Criminal Justice System", Journal of Health \& Biomedical Law, Vol. 4 No. 1, pp. 153-191.

Anasseril, D. E. (2007), "Care of the Mentally Ill in Prisons: Challenges and Solutions", Journal of the American Academy of Psychiatry and the Law Online, Vol. 35 No. 4, pp. 406-410. (accessed May 7 2016)

Baker, A.J.L. (2006), “The power of stories/stories about power: Why therapists and clients should read stories about the parental alienation syndrome", The American Journal of Family Therapy, Vol. 34, pp. 191-203. doi: 10.1080/01926180600550486 (accessed 7 May 2016)

Billington, J. (2012), “'Reading for life': prison reading groups in practice and theory”, Critical Survey, Vol. 23 No. 3, pp. 67-85.

Billington, J., Dowrick, C., Robinson, J., Hamer, A. and Williams, C. (2011), An Investigation into the Therapeutic Benefits of Reading in Relation to Depression and Well-being. Liverpool Health Inequalities Research Unit, University of Liverpool, Liverpool.

Billington, J., Carroll, J., Davis, P., Healey, C. and Kinderman, P. (2013), “A literature-based intervention for older people living with dementia", Perspectives in Public Health, Vol. 133 No.3, pp.165-173. 
Billington, J., Humphreys, A.L, Jones, A. and McDonnell, K. (2014), “A literature-based intervention for people with chronic pain", Arts \& Health. Advanced online publication. Doi: 10.1080/17533015.2014.957330 (accessed 7 May 2015)

Brooker, C., Gojkovic, D. and Sirdifield, C. (2007), Mental Health Services and Prisoners: An Updated Review, Centre for Clinical and Academic Workforce Information (CCAWI), University of Lincoln, Lincoln.

Centre for Research into Reading, Literature and Society (CRILS). (2014), Read to Care: An Investigation into Quality of Life Benefits of Shared Reading Groups for People Living with Dementia, University of Liverpool, Liverpool.

Cocking, A. and Astill, J. (2004), "Using literature as a therapeutic tool with people with moderate and borderline learning disabilities in a forensic setting", British Journal of Learning Disabilities, Vol. 32 No. 1, pp. 16-23.

Coffey, A., and Atkinson, P. (1996), Making Sense of Qualitative Data: Complementary Research Strategies, Sage, London.

Collier, L. (2014), “Incarceration Nation”, Newsletter of the American Psychological Association, October 2014, Vol 45 No. 9, p. 56. http://www.apa.org/monitor/2014/10/incarcerati on.aspx (accessed 7 May 2016)

Davidson, K., Norrie, J., Tyrer, P., Gumley, A., Tata, P., Murray, H. and Palmer, S. (2006), "The effectiveness of cognitive behaviour therapy for borderline personality disorder", Journal of Personality Disorders, Vol. 20 No. 5, pp. 450-465.

Davis, J. (2009), "Enjoying and enduring: groups reading aloud for wellbeing”, The Lancet, Vol. 373 No. 9665, pp. 714-715.

Davis, P. (2008), “Syntax and pathways”, Interdisciplinary Science Reviews, Vol. 33 No.4, pp. $265-277$. 
Davis, P., Keidel, J.L., Gonzalez-Diaz, V., Martin, C.D. and Thierry, G. (2013), “How Shakespeare tempests the brain: neuroimaging insights", Cortex, Vol. 49 No.4, pp.2164.

Department of Health. (2009), “Lord Bradley's review of people with mental health problems or learning disabilities in the criminal justice system", available at:

http://webarchive.nationalarchives.gov.uk/20130107105354/http://www.dh.gov.uk/en /Publicationsandstatistics/Publications/PublicationsPolicyAndGuidance/DH_098694 (accessed 7 May 2015).

Department of Health. (2014), Achieving Better Access to Mental Health Services by 2020, Department of Health, London.

Dowrick, C., Billington, J., Robinson, J., Hamer, A. and Williams, C. (2012), “Get into Reading as an intervention for common mental health problems: exploring catalysts for change", Medical Humanities, Vol.38 No.1, pp. 15-20.

Dwivedi, K. N. (Ed.) (1997), The Therapeutic use of Stories, Routledge, London.

Emerson, R., Fretz, R., and Shaw, L. (2007), "Participant Observation and Fieldnotes" in Atkinson, P., Coffey, A., Delamont, S., Lofland, J. and Lofland, L. (Eds.), Handbook of Ethnography, Sage, London.

Fonagy, P. (2006), “The mentalization-focused approach to social development”, in Allen, J.G. and Fonagy, P. (Eds.), Handbook of Mentalization-Based Treatment, John Wiley \& Sons, Chichester, pp. 53-100.

Fonagy, P. and Bateman, A. (2008), “The development of borderline personality disorder a mentalizing model", Journal of Personality Disorders, Vol. 22 No. 1, pp. 4-21.

Galgut, E. (2010), "Reading minds: mentalization, irony and literary engagement", International Journal of Psychoanalysis, Vol. 91 No. 4, pp. 915-35. 
Gold, J. (2001), Read for your life: Literature as a life support system, Fitzhenry \& Whiteside, Ontario.

Graham, M.A., and Pehrsson, D.E. (2008), “Bibliosupervision: A multiple-baseline study using literature in supervision settings", Journal of Creativity in Mental Health, Vol. 3 No. 4, pp. 428-440. doi: 10.1080/15401380802531052 (accessed 7 May 2016)

Gray, E., Kiemle, G., Billington, J. and Davis, P. (2016), “An Interpretative Phenomenological Analysis of the Experience of Being in a Reader Group", Arts \& Health: An International Journal for Research, Policy and Practice. doi:10.1080/17533015.2015.1121883 (accessed 7 May 2016)

Harari, H., Shamay-Tsoory, S., Ravid, M. and Levkovitz, Y. (2010), "Double dissociation between cognitive and affective empathy in borderline personality disorder", Psychiatry Research, Vol. 175 No. 3, pp. 277-279.

Hartley, J. and Turvey S. (2009), "Reading together: the role of the reading group inside prison", Prison Service Journal, Vol. 183, pp. 27-32.

Heard, E.M, Mutch, A., Fitzgerald, L. and Pensalfini, R. (2013), "Shakespeare in Prison: affecting health and wellbeing", International Journal of Prisoner Health, Vol. 9 No. 3, pp. $111-123$.

Hodge, S., Robinson, J. and Davis P. (2007), "Reading between the lines: the experiences of taking part in a community reading project”, Medical Humanities, Vol. 33 No. 2, pp. $100-104$.

Joint Prison Service and National Health Service Executive Working Group. (1999), The Future Organisation of Prison Healthcare, Department of Health, London.

Joseph, N. and Benefield, N. (2012), “A joint offender personality disorder pathway strategy: An outline summary", Criminal Behaviour and Mental Health Special Issue: Dangerous and Severe Personality Disorder and High Harm Offenders, 
Vol. 22 No. 3, pp. 210-17.

Lamb, W. (2003), Couldn't Keep It to Myself: Testimonies from our Imprisoned Sisters, Harper Collins, New York.

Lemogne, C, Piolino, P., Friszer S., Claret, A., Girault, N., Jouvent, R., Allilaire , J.F. and Fossati, P. (2006), "Episodic autobiographical memory in depression: specificity, autonoetic consciousness, and self-perspective", Consciousness and Cognition, Vol. 15 No. 2, pp. 258-268.

Longden, E., Davis, P., Billington, J., Lampropoulou, S., Farrington, G., Magee, F., Walsh, E. and Corcoran, R. (2015), "Shared Reading: assessing the intrinsic value of a literature-based health intervention." Medical Humanities, advanced online publication, doi: 10.1136/medhum-2015-010704. (accessed 7 May 2016)

Liotti, G. and Gumley, A. (2008), "An attachment perspective on schizophrenia: the role of disorganized attachment, dissociation and mentalization”, in Moskowitz, A., Schäfer, I. and Dorahy M. J. (Eds.), Psychosis, Trauma and Dissociation: Emerging Perspectives on Severe Psychopathology, Wiley-Blackwell, Chichester, pp. 117-133.

Low, G., Jones, D. and Duggan, C. (2001), "The treatment of deliberate self-harm in borderline personality disorder using dialectical behaviour therapy: a pilot study in a high security hospital”, Behavioural and Cognitive Psychotherapy, Vol 29, pp. 85-92.

McArdle, S. and Byrt, R. (2001), "Fiction, poetry and mental health: Expressive and therapeutic uses of literature", Journal of Psychiatric and Mental Health Nursing, Vol. 8, pp. 517-524.

Meins, E., Fernyhough, C., Russell, J. and Clark-Carter, D. (1998), "Security of attachment as a predictor of symbolic and mentalising abilities: a longitudinal study", Social Development, Vol. 7 No. 1, pp. 1-24. 
Mischler, E. (1986), Research Interviewing: Context and Narrative, Harvard University Press, Cambridge MA.

NICE (October, 2009), Self-Harm: the longer term management for self-harm, Clinical

\section{Guideline (Scope)}

O'Sullivan, N., Davis, P., Billington, J., Gonzalez-Diaz, V. and Corcoran, R. (2015), "'Shall I compare thee": The neural basis of literary awareness, and its benefits to cognition. Cortex, Vol. 73, pp. 144-57.

Osborne, G.B. (2012), “Writing Ethnographic Fieldnotes”, Canadian Journal of SociologyCahiers Canadiens De Sociologie, Vol 37 No 2, pp, 197-199.

Pawson R. and Tilley, N. (1997), Realistic Evaluation. Sage, London.

Pehrsson, D. E. and McMillen, P. (2005), “A bibliotherapy evaluation tool: Grounding counselors in the therapeutic use of literature", The Arts in Psychotherapy, Vol. 32, pp. 47-59. doi: 10.1016/j.aip.2004.11.001

Riessman, C. (2008), Narrative Methods for the Human Sciences, Sage, London.

Robinson, J. (2008), Reading and Talking: Exploring the Experience of Taking Part in Reading Groups in Walton Neuro-Rehabilitation Unit. HaCCRU Research Report 114/08, Liverpool.

Robinson, J. and Billington, J. (2013), An Evaluation of a Pilot Study of a Literature-Based Intervention with Women in Prison. Centre for Research into Reading, Literature and Society, University of Liverpool, Liverpool.

https://www.liverpool.ac.uk/media/livacuk/instituteofpsychology/FullPrisonReportJB March52013,.pdf (accessed 7 May)

Robinson, J. and Billington, J. (2014), An Evaluation of a Pilot Study of a Literature-Based Intervention with Women in Prison, Short Report. Centre for Research into Reading, Literature and Society, University of Liverpool, Liverpool. 
http://www.thereader.org.uk/media/73499/CRILS_Short_Report_web.pdf (accessed 7 May 2016)

Ross, M.W. (2011), "Pedagogy for prisoners: an approach to peer health education for inmates", Journal of Correct Health Care, Vol. 17 No. 1, pp. 6-18. doi: $10.1177 / 1078345810378251$.

Sanjek, R. (Ed.) (1990), Fieldnotes: The Makings of Anthropology, Cornell University Press, Ithaca.

Scott-Douglas, A. (2007), Shakespeare Inside: The Bard Behind Bars, Continuum, London.

Shaw, J., Dunn, G., Rogers, A., Thornicroft, G., Gournay K., CBE, Fahy, T., Lathlean, J., Birmingham, L., Kendall, K., Brooker, C., Jones, P. and Liebling, A. (2010), “The pathway of prisoners with mental health problems through prison health services and the effect of the prison environment on the mental health of prisoners: A report to the National Institute of Health Research”, The Offender Health Research Network. http://www.ohrn.nhs.uk/OHRNResearch/EnvPat h.pdf (accessed 7 May 2016)

Silverman, D. (2012), Interpreting Qualitative Data, Sage, London.

The Reader. (2015), "Reading for wellbeing partnership expands across North West", available at: http://www.thereader.org.uk/who-we-are/media-centre/reading-forwellbeing-partnership-expands-across-north-west.aspx (accessed 28 August 2015)

Thierry, G., Martin, C.D., Gonzalez-Diaz, V., Rezaie, R., Roberts, N. and Davis P. (2008), "Event-related potential characterisation of the Shakespearean functional shift in narrative sentence structure", NeuroImage, Vol. 40 No. 2, pp.923-931.

Thigpen, M., Solomon, L., Keiser, G.M. and Ortiz, M. (2004), “Effective Prison Mental Health Services: Guidelines To Expand and Improve Treatment”, U.S. Department of Justice National Institute of Corrections. https://s3.amazonaws.com/static.nicic.gov/Library/018604.pdf (accessed 7 May 2016) 
Torrey, E.F., Kennard, A.D., Eslinger, D., Lamb, R. and Paykel, J. (2010), “More Mentally Ill Persons Are in Jails and Prisons Than Hospitals: A Survey of the States", Treatment Advocacy Center.

Turvey, S. and Hartley, J. (2008), "What can a book do behind bars?”, The Reader, Vol. 32, pp. 60-68.

Van den Bergh, B.J., Gatherer, A. and Møller, L.F. (2009), “Women's health in prison: urgent need for improvement in gender equity and social justice", Bulletin of the World Health Organization, Vol. 87, pp. 406-406.

Walmsley, A. (2015), The Prison Book Club, Oneworld Publications, London.

Weinberg, I., Gunderson, J. G., Hennen, J. and Cutter, C. J. Jr. (2006), “Manual assisted cognitive treatment for deliberate self-harm in borderline personality disorder patients", Journal of Personality Disorders, Vol. 20 No. 5, pp. 482-492.

Williams, J.M.G. and Scott, J. (1988), “Autobiographical memory in depression”, Psychological Medicine, Vol. 18 No. 3, pp. 689-695.

Wilper, A.P., Woolhandler, S., Boyd, J.W., Lasser, K. E., McCormick, D., Bor, D.H. and Himmelstein, D.U. (2009), “The Health and Health Care of US Prisoners: Results of a Nationwide Survey", American Journal of Public Health Vol. 99 No. 4, pp. 666-672.

Table 1. Reading Record

Date Texts used




\begin{tabular}{|c|c|}
\hline Month 1 & $\begin{array}{l}\text { Tea with Birds, Joanne Harris } \\
\text { The Tyger, William Blake } \\
\text { Gold Cadillac, Mildred D. Taylor } \\
\text { Ozymandias, Percy Bysshe Shelley } \\
\text { The Plate, Roddy Doyle } \\
\text { Affliction, George Herbert } \\
\text { The Jester of Astapova, Rose Tremain } \\
\text { In a Restaurant, Aleksander Bloc }\end{array}$ \\
\hline Month 2 & $\begin{array}{l}\text { ChiReader Nry, Neil Gaiman } \\
\text { They Might Not need Me, Emily Dickinson } \\
\text { The Story of the Eldest Princess, A.S. Byatt } \\
\text { The Road not Taken, Robert Frost }\end{array}$ \\
\hline Month 3 & $\begin{array}{l}\text { The Ugly Duckling, Frank O'Connor } \\
\text { A Noiseless Patient Spider, Walt Whitman } \\
\text { Psalms, Jeanette Winterton } \\
\text { Permanent Granite Sunrise, Frank Cotterell Boyce } \\
\text { Prayer, Carol Anne Duffy }\end{array}$ \\
\hline Month 4 & $\begin{array}{l}\text { The Unforgotten Coat, Frank Cottrell Boyce } \\
\text { Kubla Khan, Samuel Taylor Coleridge } \\
\text { The Lake Isle Of Innisfree, W.B. Yeats } \\
\text { Below the Surface-Stream, Matthew Arnold } \\
\text { King Arthur in the East Riding and The Stone Beach, Simon Armitage } \\
\text { Snapshots, William Boyd } \\
\text { It ain't what you do it's what it does to you, Simon Armitage } \\
\text { The Secret Life of Walter Mitty, James Thurber } \\
\text { Big Sue and Now Voyager, Carol Anne Duffy }\end{array}$ \\
\hline Month 5 & $\begin{array}{l}\text { Cathedral, Raymond Carver } \\
\text { Wild Geese, Mary Oliver } \\
\text { The Pearl, John Steinbeck } \\
\text { Leisure, William Henry Davies } \\
\text { When in disgrace with Fortune and men's eyes, William Shakespeare } \\
\text { Beachcomber, George Mackay Brown }\end{array}$ \\
\hline Month 6 & $\begin{array}{l}\text { The Pearl, John Steinbeck } \\
\text { The Owl and the Pussycat, Edward Lear } \\
\text { One Art, Elizabeth Barrett Browning } \\
\text { Invictus, William Henley }\end{array}$ \\
\hline Month 7 & $\begin{array}{l}\text { The Pearl, John Steinbeck, } \\
\text { East End Tales, Gilda O'Neill } \\
\text { The Poison Tree, William Blake } \\
\text { Everyday Use, Alice Walker } \\
\text { Blackberry picking, Seamus Heaney } \\
\text { Swimming into the Millennium, Helen Dunmore }\end{array}$ \\
\hline Month 8 & Faith and Hope Go Shopping, Joanne Harris \\
\hline
\end{tabular}




\begin{tabular}{|c|c|}
\hline & $\begin{array}{l}\text { Flight, Doris Lessing } \\
\text { October's Bright Blue Weather, Helen Hunt Jackson } \\
\text { Skellig, David Almond } \\
\text { The Schoolboy, William Blake } \\
\text { Great Expectations, Charles Dickens } \\
\text { Ode to Autumn, John Keats } \\
\text { Evening, Rilke }\end{array}$ \\
\hline Month 9 & $\begin{array}{l}\text { Skellig, David Almond } \\
\text { Dulce et Decorum Est, Wilfred Owen } \\
\text { The Angel, William Blake } \\
\text { Daffodils, William Wordsworth } \\
\text { Great Expectations, Charles Dickens } \\
\text { To Any Dead Officer, Siegfried Sassoon } \\
\text { Ode to a Nightingale, John Keats }\end{array}$ \\
\hline Month 10 & $\begin{array}{l}\text { Great Expectations and A Christmas Carol, Charles Dickens } \\
\text { Skellig, David Almond }\end{array}$ \\
\hline Month 11 & $\begin{array}{l}\text { Holes, Louis Sachar } \\
\text { Lines for Winter, George Bernard Shaw } \\
\text { Break, Break, Break, Alfred Lord Tennyson } \\
\text { Great Expectations, Charles Dickens } \\
\text { A Man's A Man, Robert Burns } \\
\text { Lizard, D H Lawrence }\end{array}$ \\
\hline Month 12 & $\begin{array}{l}\text { Kes, Barry Hines } \\
\text { The Horses, Ted Hughes } \\
\text { The Bright Field, R.S. Thomas } \\
\text { Great Expectations, Charles Dickens } \\
\text { Sonnet 116, William Shakespeare } \\
\text { What You Pawn I Will Redeem and Poverty of Mirrors, Sherman Alexie } \\
\text { Head of English, Carol Anne Duffy } \\
\text { I Used to Iron Everything, Vikki Feaver } \\
\text { He Wishes for the Cloths of Heaven, W.B. Yeats } \\
\text { Postcard, Alice Munro } \\
\text { Promises Like Pie Crust, Christina Rossetti } \\
\text { Kes, Barry Hines } \\
\text { Life, Henry Van Dyke } \\
\text { Darkling Thrush, Thomas Hardy }\end{array}$ \\
\hline
\end{tabular}

Figure 1. Attendance rates for the two groups.

\begin{tabular}{|l|}
\hline \multicolumn{1}{|c|}{ Group $1(\mathrm{n}=14)$} \\
\hline Attendance rates bor participants \\
who were resident at HMP Low \\
Newton for all 41 sessions (with \\
opportunity, therefore, to attend all \\
$41)(\mathrm{n}=5)$
\end{tabular}

\begin{tabular}{|l|l|}
\hline \multicolumn{2}{|c|}{ Group $2(\mathrm{n}=16)$} \\
\\
\begin{tabular}{|l|} 
Attendance rates forlparticipants \\
resident at Low Newton for all 35 \\
sessions (with opportunity, \\
therefore, to attend all 35) $(\mathrm{n}=8)$
\end{tabular} \\
$70 \%(\mathrm{n}=1)$ & 32 \\
\hline
\end{tabular}


Attendance rates for participants released or transferred after study commencement (resident at Low Newton for only part of the study with opportunity, therefore, to attend only a proportion of the 41 sessions) $(n=9)$

Present 7 months $(\mathrm{n}=2): \quad 7 \% \& 75 \%$ Present 5 months $(\mathrm{n}=1): 90 \%$ Present 4 months $(\mathrm{n}=1): 44 \%$ Present 3 months: $(\mathrm{n}=1$ : $92 \%$ Present 10 weeks: $(n=1): 90 \%$ Present 8 weeks: $(n=1): \quad 88 \%$ Present 7 weeks: $(n=1) \quad 57 \%$ Present 5 weeks: $(n=1) \quad 100 \%$
Attendance rates for participants released or transferred after study commencement (resident at Low Newton for only part of the study with opportunity, therefore, to attend only a proportion of the 35 sessions) $(n=8)$

Present 9 months $(\mathrm{n}=1): 86 \%$ Present 4months $(\mathrm{n}=1): 81 \%$ Present 10 weeks $(n=1): 83 \%$ Present 6 weeks $(n=1): 67 \%$ Present 7 weeks $(n=1): 100 \%$ Present 5 weeks $(n=1): 100 \%$ Present 4 weeks $(n=2): 100 \% \& 100 \%$ 